\title{
Compatibilidade da Arborização de Ruas da Avenida Celestino Cavalheiro, São Gabriel-RS
}

\author{
Italo Filippi Teixeira, Rafael Machado da Silva, Giovana Lucas Tatsch \\ Universidade Federal do Pampa - UNIPAMPA
}

\begin{abstract}
RESUMO
O objetivo deste trabalho foi analisar a compatibilidade da vegetação que compõe a arborização da Avenida Celestino Cavalheiro, São Gabriel-RS, com as estruturas urbanas. Foi realizado um censo da vegetação e das estruturas urbanas que a envolvem. Os resultados demonstraram que a maioria dos indivíduos caracteriza-se como tendo origem exótica, está localizada no canteiro central, possui porte adulto e apresenta ampla área livre de pavimentação. Esses exemplares distam 0,30 m do meio-fio, possuem entre 3 a 4,9 m de altura, com fuste de 1,1 a $2 \mathrm{~m}$, gerando, dessa forma, interferência no trânsito.
\end{abstract}

Palavras-chave: arborização de ruas, São Gabriel-RS, ausência/presença de conflitos.

\section{Compatibility of Urban Trees on Celestino Cavalheiro Avenue, Sao Gabriel-RS}

\begin{abstract}
The objective of this study was to examine the compatibility of the vegetation that makes up the afforestation of Celestino Cavalheiro Avenue in Sao Gabriel, State of Rio Grande do Sul with the urban structures that surround it. For this, assessments of the vegetation and the urban structures of the location were carried out. The results showed that the majority of individuals were characterized for having exotic origin and being located in the avenue median; presenting adult possession and large open area of pavement. The individuals are located $0.30 \mathrm{~m}$ off the curb and are between 3 and $4.9 \mathrm{~m}$ tall, with 1.1 to 2 trunks; thus generating traffic interference.
\end{abstract}

Keywords: street trees, Sao Gabriel-RS, absence/presence of conflicts.

\section{INTRODUÇÃO}

A cidade de São Gabriel-RS apresenta-se como uma organização muito complexa, constituída por um conjunto de edificações e espaços livres. Os referidos espaços constituem uma rede articulada, por onde as pessoas se movimentam, e apresentamse ajustados às múltiplas funções que desempenham, caracterizando-se por tipologias específicas, adaptadas a toda a espécie de necessidades e proporcionando vivências indispensáveis à vida equilibrada do homem (Rego, 1984).
A vegetação possui um papel importante como elemento estruturante e de percepção da paisagem, demarcando, de forma inequívoca, a diferenciação dos espaços construídos e dos espaços abertos da cidade. Funciona como elemento que, por meio de suas formas, cores, texturas e atribuição estética, pode sinalizar, reforçar ou induzir percursos, criando e sugerindo momentos de parar, de ver, de se sentar, de se surpreender, reforçando qualidades cênicas, contribuindo para a coreografia geográfica e subjetiva 
dos cidadãos e, consequentemente, para conforto e melhoria da qualidade de vida (Pereira, 2006).

A arborização no espaço da malha urbana satisfaz, em primeira instância, as necessidades estéticas e de conforto climático. A preservação, a conservação e a restauração do estrato arbóreo do ecossistema local, seja ele natural ou antrópico, devem ser consideradas como um valor intrínseco de qualidade de vida e parte integrante do patrimônio ambiental e paisagístico das cidades (Chacel, 2004).

A arborização urbana explica-se por meio da sociedade que a produz. Em outras palavras, pode-se dizer que é um produto da história das relações materiais dos homens e que, a cada momento, adquire uma nova dimensão, específica de um determinado estágio do processo de trabalho objetivado e materializado. Tal processo, por um lado, aparece por meio da relação entre o construído (casas, ruas, avenidas, estradas, edificações, praças e parques) e o não construído (o natural); por outro lado, aparece pelo movimento, no que se refere ao deslocamento de homens e mercadorias, como signos que representam momentos históricos diferentes, produzindo assim uma interação entre as vias de circulação e a vegetação da cidade (Bonametti, 2003).

Essa vegetação que convive com a estrutura urbana, conforme Mascaró \& Mascaró (2010), caracteriza os espaços da cidade por suas formas, cores e modo de agrupamento; são elementos de composição e de desenho urbano ao contribuírem para organizar, definir e até delimitar esses espaços.

Os espaços verdes urbanos, em particular as árvores e florestas urbanas, podem minimizar muitos dos impactes ambientais decorrentes do crescimento urbano das seguintes formas: moderando o clima; reduzindo os consumos de energia nos edifícios, bem como as quantidades de dióxido de carbono atmosférico; melhorando a qualidade do ar; diminuindo a quantidade de águas pluviais para escoamento e minorando, consequentemente as inundações; baixando os níveis de ruído, e proporcionando habitat para a vida selvagem (Magalhães, 2001; McPherson et al., 1994; Nowak, 2001).

Por meio da sua beleza e do seu significado, as árvores fornecem qualidade de vida e riqueza no meio citadino. As árvores, os espaços arborizados e a vegetação associada providenciam numerosos usos e benefícios (Miller, 1983).

Conforme Flores (2005), as árvores, por suas características próprias, apresentam um grande potencial para oferecer atributos de qualidade aos espaços, públicos e privados, abertos. As formas estruturais naturais das árvores, por sua altura e porte, permitem dividir e hierarquizar espaços, alcançando a criação de uma imagem e uma organização urbanas únicas, com valores naturais. Conjuntamente, são elementos dinâmicos que se transformam continuamente pela sua fenologia, por meio da qual oferecem, ao longo do ano, uma variedade de texturas, coloração e densidade de copa, presença de flores e frutos, transformando estacionalmente a aparência de um mesmo lugar.

As condições ambientais que as árvores encontram nacidade apresentam outras adversidades, incluindo modificações no clima, na qualidade do ar, etc., quando comparadas com ambientes não urbanizados; assim, as árvores encontram-se sujeitas a alterações registradas no nível da luz e do ruído urbano. A gestão e a manutenção da arborização urbana é, por tudo isso, uma tarefa que constitui um desafio não apenas pelas condições difíceis que a cidade oferece ao crescimento das árvores, mas também pelos frequentes conflitos urbanos com que a localização das árvores se depara (Almeida, 2006).

Outra condição para implantação da arborização urbana são os ambientes hostis que a cidade representa para o desenvolvimento vegetal dos exemplares arbóreos, dentre os quais podem ser destacados: poluição atmosférica, contaminações de solo, falta de espaço suficiente e injúrias mecânicas feitas pelo homem ou mesmo por veículos. Esses fatores diminuem a sobrevivência e a expectativa de vida desses vegetais. As árvores implantadas em passeio público ainda sofrem interferência de pavimentação inadequada, estrangulamento dos canteiros e raízes em conflito com redes de gás, água e outras tubulações de concessionárias de serviços públicos. Ocorre, então, uma situação em que provavelmente as agressões constantes fazem dessas árvores indivíduos mais frágeis do que aqueles que poderiam ser encontrados em seu habitat natural. Muitas vezes, essas árvores não conseguem atingir 
a maturidade, ficando restritas ao estado juvenil de desenvolvimento.

Desse modo, a arborização urbana ganharia restrições, devendo ser planejada de acordo com a disponibilidade das áreas, além de levar em conta as vias para os pedestres e os padrões variados de pavimentação, combinados com os componentes dos mobiliários e equipamentos urbanos. Quando os conflitos, em determinado espaço urbano, tornam-se muito evidentes, faz-se necessária uma análise para se revitalizar esse espaço, criando um ambiente que integre o meio às novas expectativas socioculturais e funcionais, para então surgir um novo espaço paisagístico com elevado grau de legitimidade, o que melhoraria, sem dúvida, a qualidade de vida da população (Bonametti, 2003).

Para estimar os benefícios, as relações entre a estrutura da floresta urbana (arranjos entre as árvores e outros componentes das cidades, como, por exemplo, os prédios) e os processos ecológicos estudados precisam ser conhecidas (Nicodemo \& Primavesi, 2009).

O conhecimento e a análise das estruturas das cidades e suas funções, por meio das óticas econômica, social e ambiental, são pré-requisitos básicos para o planejamento e a administração das áreas urbanas, na busca de melhores condições de vida para os seus habitantes. Nesse contexto - e pelos seus próprios objetivos -, a arborização urbana assume importância particular (Rocha et al., 2004).

Colocados esses aspectos, o objetivo deste estudo é a análise da compatibilidade da vegetação inventariada com a estrutura urbana presente na Avenida Celestino Cavalheiro, São Gabriel-RS.

\section{METODOLOGIA}

O município de São Gabriel está localizado na fronteira oeste, região da campanha gaúcha, com coordenadas de $30^{\circ} 20^{\prime} 09^{\prime \prime} \mathrm{S}$ e $54^{\circ} 19^{\prime} 12^{\prime \prime} \mathrm{O}$, junto à Rodovia BR-290, a $320 \mathrm{~km}$ da capital do Estado do Rio Grande do Sul (Figura 1). Possui uma população de 60.508 habitantes, sendo que ocorre uma concentração de $89 \%$ na área urbana, segundo o IBGE (Instituto..., 2011).

Com altitude de $114 \mathrm{~m}$ acima do nível do mar, o município possui clima subtropical, com altas temperaturas no verão, chegando a $34^{\circ}$, e temperaturas muito baixas no inverno. A média de temperatura anual é de $19^{\circ} \mathrm{C}$. A topografia é de áreas planas com pequenas declividades e a vegetação é predominantemente de campos. Possui solo Planossolo Háplico eutrófico típico (SXe), originado do siltito.

Seus limites compreendem os municípios de Rosário do Sul, Lavras do Sul, Dom Pedrito, Cacequi, Dilermando de Aguiar, Santa Margarida do Sul, São Sepé e Santa Maria.

O local objeto de estudo é a Avenida Celestino Cavalheiro (Figura 2), que se caracteriza como uma importante via do município, com aproximadamente $2 \mathrm{~km}$ de extensão e duas pistas de $6 \mathrm{~m}$ de largura cada, que une áreas comerciais, residenciais e hospitalares, resultante da bifurcação da Avenida Antonio Trilha, artéria principal de entrada no município. Possui as linhas de transmissão de energia de baixa e média tensão localizadas no canteiro central, assim como de outras prestadoras de serviços.

Na referida avenida, foi desenvolvido um censo qualiquantitativo e, por meio de um instrumento estruturado, inventariaram-se as seguintes variáveis para a caracterização da vegetação e do ambiente em torno da mesma: localização na via: cc-canteiro central; c-calçada; espécie; origem: n-nativa da região; e-exótica; porte da espécie: pequena-espécie arbórea ou arbustiva com altura até 2,0 m; médiaespécie arbórea ou arbustiva com altura entre 2,01 até 5,0 m; grande-espécie arbórea com altura superior a 5,0 m; área livre de pavimentação: superfície livre de pavimentação na calçada destinada ao plantio de espécie arbóreo-arbustiva e que permite a passagem de água da chuva, aeração do solo e adubações futuras: ampla-A: área livre igual ou superior a $1 \mathrm{~m}^{2}$; regular-RG: igual a $0,5 \mathrm{~m}^{2}$; restrita-RS: área livre inferior a $0,5 \mathrm{~m}^{2}$; inexistente-I: quando a área pavimentada encobre todo o colo da planta; distância do meio-fio-DMF: distância da parte interna do meio-fio em metros à muda; altura total-HT: em m; altura do fuste-HF: altura até a inserção do primeiro galho vivo, em $\mathrm{m}$; interferência da copa: sem interferência no trânsito de pedestres e/ou veículos; com interferência no trânsito de pedestres e/ou veículos; ausência/presença de conflitos: conflitos do vegetal com o espaço tridimensional onde está 


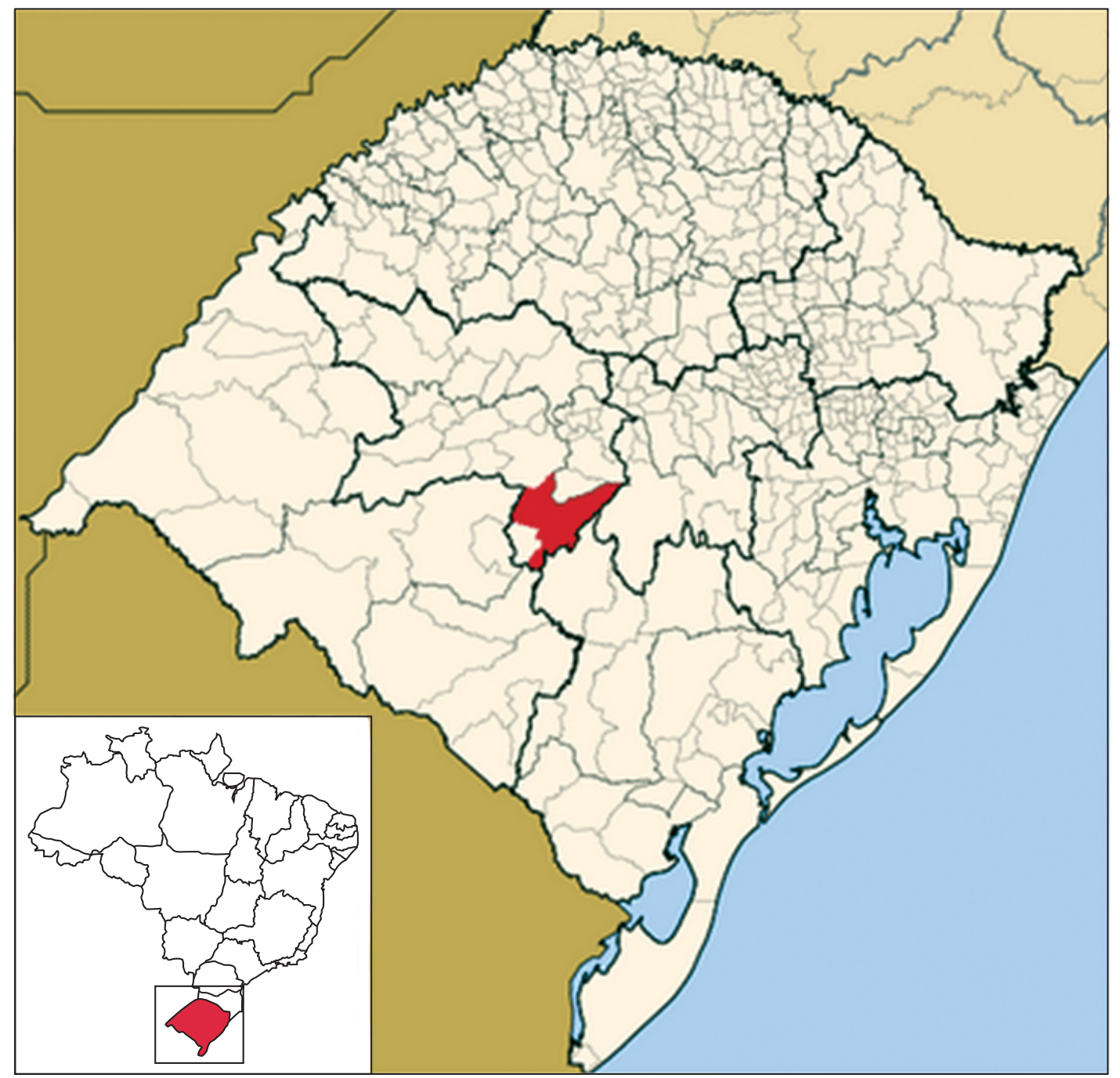

Figura 1. Localização do município de São Gabriel-RS.

Figure 1. Localization of the municipality of São Gabriel-RS.

localizado em relação a estruturas, como muros, fiação elétrica, postes diversos, construções e outras formas de vegetação: compatível-C: quando o espaço que o comporta permite o seu desenvolvimento sem necessidade de intervenção mecânica; medianamente compatível-MC: requer poda leve, porém sistemática para controle do tamanho e da forma da copa; pouco compatível-PC: requer poda pesada e sistemática para controle do tamanho e da forma da copa; incompatível-I: quando o desenvolvimento do vegetal está comprometido em função de estruturas, como muros, fiação elétrica, postes diversos, construções e outras formas de vegetação, e sua permanência poderá incorrer em um desenvolvimento inadequado ou até mesmo em riscos para essas estruturas e para a população em geral.

\section{RESULTADOS}

Na Tabela 1, observa-se a distribuição da vegetação arbóreo-arbustiva inventariada na Avenida Celestino Cavalheiro, São Gabriel-RS, que se caracteriza pela maciça presença da classe exótica, sendo que as espécies já tradicionais na arborização de ruas ocorrem com as maiores frequênciasLigustro (39,55\%) e Extremosa (28,35\%) -, perfazendo juntas $67,9 \%$ da arborização. 


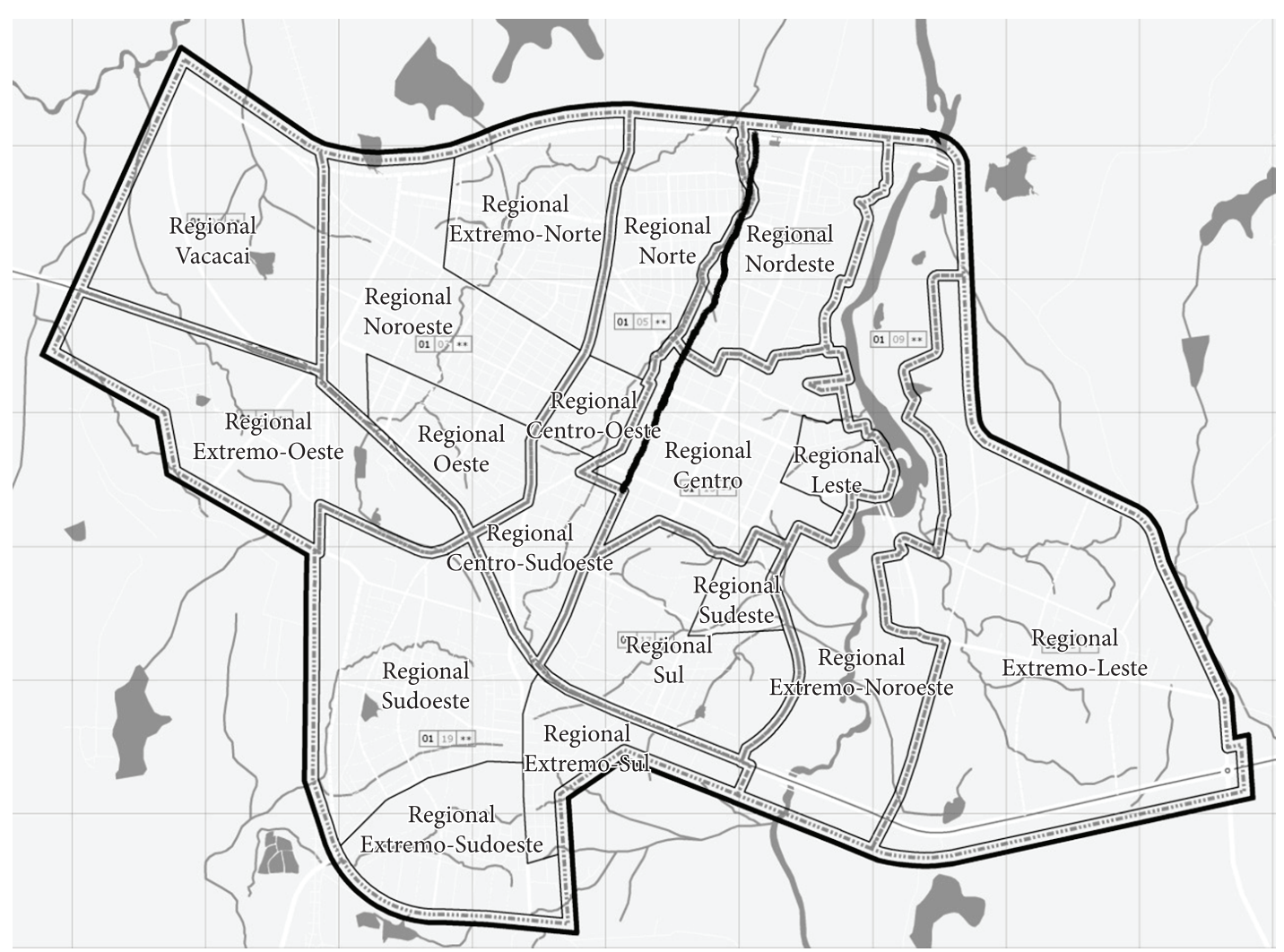

Figura 2. Localização da Avenida Celestino Cavalheiro (em preto) na área urbana de São Gabriel-RS.

Figure 2. Localization of Celestino Cavalheiro Avenue (black) in the urban area of São Gabriel-RS.

Com situação semelhante, embora inventariando a composição da arborização de duas vias da cidade de Mariópolis-PR, Silva et al. (2008) identificaram no Ligustrum japonicum Thunb a maior frequência, com um total de 54\% em 20 espécies.

No município de Passo Fundo-RS, Melo \& Severo (2010) também encontraram uma grande concentração de exemplares de Ligustrum lucidum W. T. Aiton, 37,23\%, compondo a arborização da Avenida Brasil, principal via de acesso à referida cidade.

Diferentemente das situações em que se identificou, nas espécies exóticas, a maior frequência, Cruz et al. (2008), ao analisarem qualiquantitativamente a arborização da Avenida Marechal Castelo Branco, em Teresina-PI, obtiveram em uma espécie nativa, Copernicia cerifera Mart., um expressivo predomínio com $86,3 \%$ do total de exemplares.

Turra et al. (2010), ao analisarem os resultados do censo na Avenida das Acácias, São Gabriel-RS, observaram também uma grande concentração de exemplares em poucas espécies, principalmente na Lagerstroemia indica L., com 19,27\% do total.

Silva (2000) relata que é comum, na arborização urbana, que poucas espécies representem a maior parte da população, mesmo não sendo esta uma situação desejável, quer por razões estéticas ou fitossanitárias.

A única espécie autóctone da região de São Gabriel-RS e que tem ocorrência na arborização da referida avenida é o Ipê-roxo, que contribui com apenas $4,2 \%$ de frequência no total da vegetação presente. Por meio de observações in loco, os autores analisaram a vegetação e verificaram que esta possui muitos indivíduos jovens em franco processo de desenvolvimento.

A arborização de Porto Alegre-RS, iniciada no século XIX, conta com 180 espécies. A idade média das árvores é de 60 a 70 anos. No passado, as espécies exóticas foram dominantes. Fruto de uma política de valorização das espécies nativas no paisagismo, essa 
Tabela 1. Valores de frequência absoluta e relativa, localização e origem das espécies identificadas no censo da Avenida Celestino Cavalheiro, São Gabriel-RS.

Table 1. Values of absolute and relative frequency, localization and origin of the species identified in the census of Celestino Cavalheiro Avenue, São Gabriel-RS.

\begin{tabular}{|c|c|c|c|c|c|c|c|}
\hline \multirow{2}{*}{$\begin{array}{c}\text { Nome } \\
\text { comum }\end{array}$} & \multirow{2}{*}{$\begin{array}{c}\text { Nome } \\
\text { botânico }\end{array}$} & \multicolumn{2}{|c|}{ Localização } & \multicolumn{2}{|c|}{ Origem } & \multicolumn{2}{|c|}{ Frequência } \\
\hline & & $\mathbf{C}$ & $\mathrm{CC}$ & $\mathbf{N}$ & $\mathbf{E}$ & Abs & Rel \\
\hline Ligustro & Ligustrum japonicum Thunb.. & 5 & 48 & & $\mathrm{X}$ & 53 & 39,55 \\
\hline Extremosa & Lagerstroemia indica $\mathrm{L}$ & & 38 & & $\mathrm{X}$ & 38 & 28,35 \\
\hline Pingo-de-ouro & Duranta repens $\mathrm{L}$. & & 16 & & $\mathrm{X}$ & 16 & 11,93 \\
\hline Ipê-roxo & Handroanthus heptaphyllus (Vell.) Mattos & & 5 & $\mathrm{X}$ & & 5 & 3,73 \\
\hline Ficus & Ficus benjamina $\mathrm{L}$. & 1 & 2 & & $\mathrm{X}$ & 3 & 2,38 \\
\hline Limoeiro & Citrus aurantifolia (Christm.) Swingle & & 2 & & $\mathrm{X}$ & 2 & 1,48 \\
\hline Canafístula & Peltophorum dubium (Sprengel) Taubert) & & 2 & $\mathrm{X}$ & & 2 & 1,48 \\
\hline Figueira & Ficus clusiifolia Schott & 2 & & $\mathrm{X}$ & & 2 & 1,48 \\
\hline Goiabeira & Psidium guajava L. & & 2 & $\mathrm{X}$ & & 2 & 1,48 \\
\hline Cheflera & Schefflera actinophylla (Endl.) .A.T.Harms & & 2 & & $\mathrm{X}$ & 2 & 1,48 \\
\hline Espirradeira & Nerium oleander L. & & 1 & & $\mathrm{X}$ & 1 & 0,74 \\
\hline Amendoim-bravo & Pterogines nitens Tul & 1 & & $\mathrm{X}$ & & 1 & 0,74 \\
\hline Angico-vermelho & Parapiptadenia rigida (Benth.) Brenan & & 1 & $\mathrm{X}$ & & 1 & 0,74 \\
\hline Pitangueira & Eugenia uniflora L. & & 1 & $\mathrm{X}$ & & 1 & 0,74 \\
\hline Cinamomo & Melia azedarach L. & & 1 & & $\mathrm{X}$ & 1 & 0,74 \\
\hline Ingá & Inga marginata Wild & & 1 & $\mathrm{X}$ & & 1 & 0,74 \\
\hline Brunfelsia & Brunfelsia uniflora (Pohl.) D. Don & & 1 & $\mathrm{X}$ & & 1 & 0,74 \\
\hline Pessegueiro & Prunus persica (L.) Batsch. & & 1 & & $\mathrm{X}$ & 1 & 0,74 \\
\hline Chapéu-de-napoleão & Thevetia peruviana (Pers). K. Schum. & & 1 & & $\mathrm{X}$ & 1 & 0,74 \\
\hline & Total & & & & & 134 & 100 \\
\hline
\end{tabular}

tendência vem sendo mudada e, atualmente, cerca de $47 \%$ do total de espécies plantadas são nativas brasileiras (Menegat et al., 1999).

Duryea et al. (1996) consideram que árvores nativas podem oferecer vantagens quando comparadas às exóticas, principalmente no que diz respeito à adaptação local. Entretanto, a diversidade de espécies entre nativas e/ou exóticas pode melhorar a beleza estética, na medida em que limita perdas por doenças específicas das espécies ou por ataque de insetos. A utilização de espécies exóticas pode contribuir para a diversidade, mas, por outro lado, o uso de espécies introduzidas sem o conhecimento das características morfofisiológicas e silviculturais pode gerar problemas futuros para a manutenção das árvores, além de se correr o risco de se tornarem espécies indesejáveis para as condições urbanas.

No que tange à localização dos exemplares inventariados, os valores demonstrados na Tabela 1 deixam clara a maciça concentração dos mesmos no canteiro central, pois, dos 134 exemplares, apenas nove estão em calçadas. Esse fato é de suma importância nesta análise da compatibilidade dessa vegetação com a infraestrutura urbana, pois a fiação de baixa e média tensão, assim como a telefonia, estão localizadas exatamente no canteiro central da referida avenida. Essa situação por si já é um grande fator limitante do desenvolvimento da vegetação presente, pois a mesma é do tipo convencional, não possuindo qualquer tipo de proteção; note-se que os espaços livres no entorno dessas árvores são constantemente monitorados e motivo de podas, nem sempre efetuadas por empresas capacitadas e com resultados satisfatórios.

De uma realidade em que as podas realizadas geralmente são drásticas, acabam por decorrer inúmeros problemas, como a total ausência dos benefícios proporcionados pelas espécies de grande porte, substituídas pelas plantas pequenas ou arbustivas, quanto ao fornecimento de sombra e todo um decorrente fator ecológico de relevância nas atuais áreas urbanas. Outro fato problemático é que os danos causados às árvores por podas mal feitas 
são muitos, prejudicando não somente o próprio espécime vegetal, que geralmente foi mutilado, mas também podendo ocasionar a perda de sua estabilidade e consequente tombamento sobre casas, carros e fiações, trazendo transtornos de todo o tipo. Além disso, a poda em árvores urbanas é um dos principais motivos de perda do exemplar, sendo alto o número de árvores que morrem após tal operação (Velasco, 2003).

O porte da vegetação estabelece o seu potencial de conflito com equipamentos, transeuntes e outros tipos de vegetação do entorno, potencialmente afetando a arquitetura de sua copa e gerando problemas de ordem fitossanitários. O resultado do censo realizado demonstrou, segundo a Figura 3, que a maioria encontra-se na classe grande, com 98 indivíduos, conforme o porte de cada espécie quando adulta e considerando-se as condições de crescimento em áreas urbanas, assim como as classes média e pequena concentram 36 dos indivíduos, necessitando de um monitoramento no seu crescimento para que as intervenções silviculturais, principalmente a poda, sejam eficientes no tocante ao resultado final.

Martins (2010), em trabalho desenvolvido na arborização da cidade de Luiziana-PR, ao segregar os vegetais em classes de alturas, constatou que quanto maior o porte arbóreo, maior o grau de interferência entre árvore e rede elétrica. Verificou que 100\% das espécies vegetais que possuíam altura de até $3 \mathrm{~m}$ não apresentavam nenhum tipo de interferência com fiação, visto que a altura mínima prevista para cabos

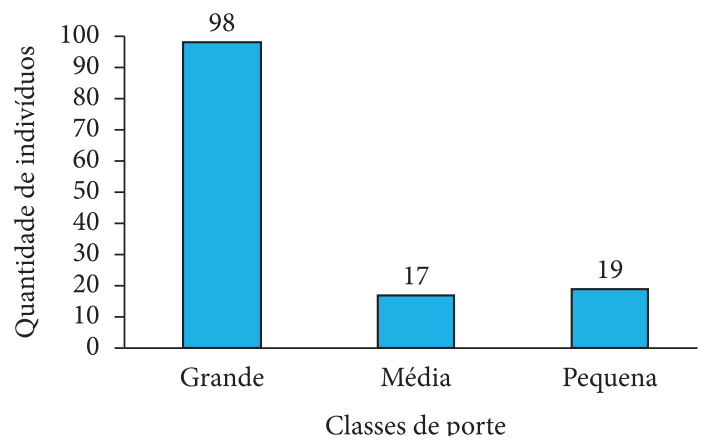

Figura 3. Distribuição das classes de porte dos exemplares da arborização da Avenida Celestino Cavalheiro, São Gabriel-RS e frequências relativas.

Figure 3. Size class distribution of exemplary the arborization of Celestino Cavalheiro Avenue, São Gabriel-RS and relative frequencies. de telefonia (os quais são os mais baixos) é de 5,40 m. Na classe em que o porte arbóreo oscilou de 3,1 a 6 m, verificou $37 \%$ de interferência junto à fiação; ainda assim, essa classe de altura, quando bem manejada, apresenta menores riscos de contato: verificou-se, nessa classe, que 63\% das árvores não apresentaram nenhum tipo de interferência. Na classe que oscilou entre 6,1 e 9 m, verificou 96\% de interferência entre a copa da arvore e a fiação; nos portes entre 9,1 e $12 \mathrm{~m}$, esse percentual caiu para $89 \%$ de interferência; nas classes que variam de 12,1 a $15 \mathrm{~m}$ e de 18,1 a $21 \mathrm{~m}$, estatisticamente, obteve-se interferência de $100 \%$. Para a classe de altura entre 15,1 e 18 m, não se evidenciou a existência de nenhum indivíduo sob a rede elétrica. Verificou, então, que a classe de altura entre 6,1 e 9 m é a que mais apresenta interferência junto à fiação; tal fato acontece em razão de a rede elétrica situar-se nessa faixa de altura, fazendo-se necessário constante manejo nessa classe de altura, com o intuito de se evitarem eventuais danos.

Na Avenida Celestino Cavalheiro, São GabrielRS, observa-se que a maioria da vegetação, 65, possui uma área livre de pavimentação ampla para o seu desenvolvimento, conforme a Figura 4. Essa informação, inicialmente, traduz uma condição favorável ao desenvolvimento da vegetação, porém esses valores correspondem ao fato de que esta ocupa, em grande parte, o canteiro central e se veem parcos plantios efetuados nas calçadas, conforme Tabela 1 . Embora a localização da vegetação inventariada esteja concentrada no canteiro central, o mesmo apresenta variações de largura ao longo do trajeto

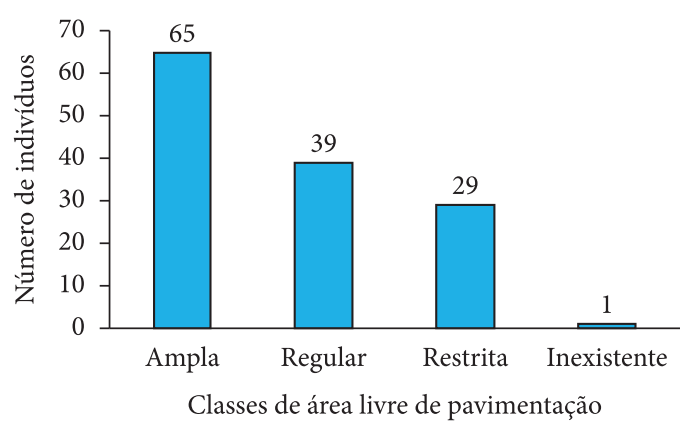

Figura 4. Distribuição das classes de área livre dos exemplares da arborização da Avenida Celestino Cavalheiro, São Gabriel-RS e frequências relativas.

Figure 4. Distribution class of free area exemplary of tree planting Celestino Cavalheiro Avenue, São Gabriel$\mathrm{RS}$ and relative frequencies. 
dessa via, gerando dessa forma o agrupamento dentre as diferentes classes.

Conforme Raber \& Rebelato (2010), a falta de área livre (espaço livre que permite a infiltração de águas e nutrientes para a planta) provoca um mau desenvolvimento das plantas e a utilização de espécies com sistema radicular pouco profundo numa área pequena pode comprometer a calçada, em função da pressão exercida pelas raízes.

Na Figura 5, observa-se a ocorrência de dez classes de distância do meio-fio. A maioria encontrase na classe de distância com $0,30 \mathrm{~m}$, com 26 dos indivíduos inventariados.

Santiago (1970) recomenda como ideal uma distância das árvores ao meio fio entre 30 e $40 \mathrm{~cm}$; o Departamento de Parques e Jardins de Curitiba (1977) considera que essa distância não deve ser menor que $1 \mathrm{~m}$, para se evitarem danos físicos às árvores provocados pelos veículos.

A análise da classe de altura total, conforme a Figura 6, revela que a maioria da vegetação, 62 indivíduos, possui entre 3 e 4,9 m de altura total, demonstrando a potencialidade de intervenções silviculturais para uma adequação espacial em razão do volume de trânsito de veículos de grande porte e também em função da maioria da vegetação estar no canteiro central, onde se localiza a fiação aérea tanto de baixa como de alta tensão.

Em estudos realizados por Rocha et al. (2004) em dois bairros de Nova Iguaçu, no Estado do Rio de Janeiro, observou-se que cerca 64 e 51\% das árvores de cada bairro apresentavam altura inferior a $6 \mathrm{~m}$ e

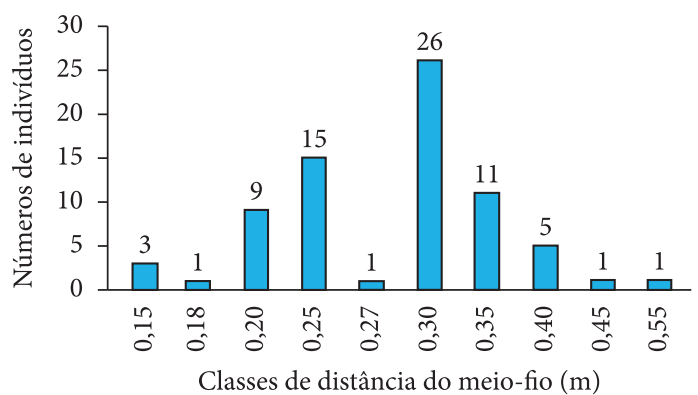

Figura 5. Distribuição das classes de distância do meio fio até exemplares da arborização da Avenida Celestino Cavalheiro, São Gabriel-RS e frequências relativas.

Figure 5. Distribution of class distance from the curb to exemplary arborization Celestino Cavalheiro Avenue, São Gabriel-RS and relative frequencies. cerca de 10 e $18 \%$ das árvores tinham altura superior a $8,8 \mathrm{~m}$

Essa situação também foi verificada por Rodolfo Júnior et al. (2008) em Pombal-PB, onde dois dos três bairros apresentaram na composição de suas ruas inventariadas percentuais de 23 a 35\% de árvores com altura total inferior a $5 \mathrm{~m}$.

O fuste caracteriza-se por ser a região entre o colo da planta e a primeira inserção de galho vivo. Dentro dessa perspectiva e considerando-se as características da via e a posição da maioria da vegetação, qual seja o canteiro central, torna-se preocupante saber que 82 indivíduos possuem fuste na classe de 1,1 a $2 \mathrm{~m}$ (Figura 7). Tal fato remete também à condição de plantas ainda jovens, porém em crescimento e sem condução alguma, potencializando-se futuros danos e incompatibilidade com veículos de pequeno porte, inclusive.

Em Oslo, Noruega, 49\% das árvores de rua analisadas apresentaram danos visíveis no tronco, sendo que 2,2\% apresentaram graves danos ao tronco com pequena chance de recuperação, tendo sido a maioria dos danos provocados por veículos (Fostad \& Pedersen, 1997).

Sampaio (2006), ao analisar a arborização das vias públicas das principais zonas do plano piloto de Maringá-PR, obteve a altura média da primeira bifurcação de 2,07 m. Diferentemente do dado encontrado por Milano (1988) no estudo da arborização de toda cidade de Maringá-PR, que obteve uma média de $1,8 \mathrm{~m}$, porém semelhante ao

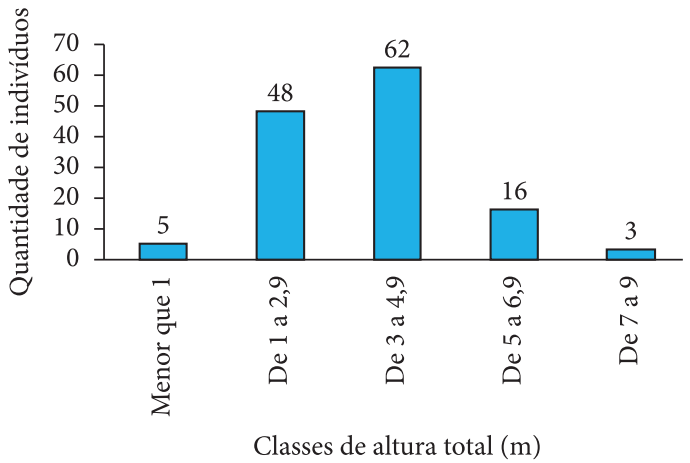

Figura 6. Distribuição das classes de altura total dos exemplares da arborização da Avenida Celestino Cavalheiro, São Gabriel-RS e frequências relativas.

Figure 6. Class distribution the total height tree planting Celestino Cavalheiro Avenue, São Gabriel-RS and relatives frequencies. 


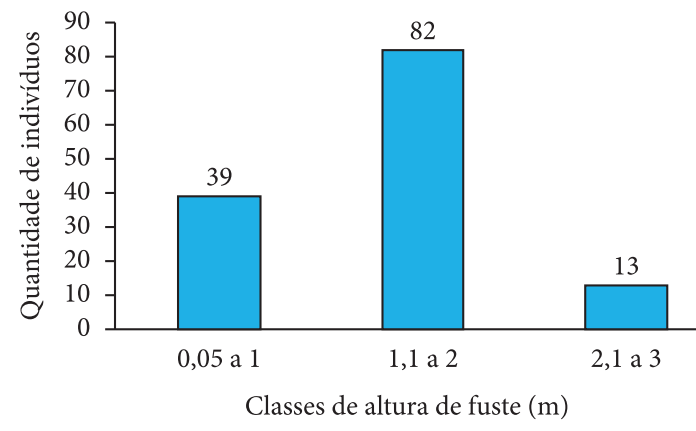

Figura 7. Distribuição das classes de altura de fuste dos exemplares da arborização da Avenida Celestino Cavalheiro, São Gabriel-RS e frequências relativas.

Figure 7. Distribution of height class of samples from bole tree planting Celestino Cavalheiro Avenue, São Gabriel-RS and relative frequencies.

encontrado por Biondi (1985) em Recife-PE, cuja média foi de $2,2 \mathrm{~m}$.

$\mathrm{Na}$ Figura 8, observa-se que a maioria dos indivíduos, 77, apresenta interferência no trânsito no caso, de veículos automotores -, em razão de a sua distribuição estar concentrada no canteiro central, gerando danos em função da inexistência de podas de condução. Tal situação contribui para redução da vida útil dos exemplares por causa dos constantes danos tanto nas folhas formadoras da copa como também nos ramos.

Esse fato é corroborado por uma largura do leito carroçável com diferenças entre as quadras inventariadas, partindo do valor de 8,35 até $6 \mathrm{~m}$, caracterizando a Avenida como uma via estreita, com presença de estacionamento lateral; promovese, com isso, uma circulação mais intensa e com maior proximidade da área do canteiro central, o que vem acarretar danos principalmente nas copas das espécies vegetais de maior porte.

Da Silva (2009), analisando quatro avenidas do município de Foz do Iguaçú-PR, constatou que $75 \%$ dos exemplares inventariados apresentavam problemas de interferência no trânsito.

Dentre as situações inadequadas e presentes nos conflitos da arborização urbana no município de Colorado-RS, podem-se destacar o avanço da copa para a rua, o avanço da copa para a casa, os entrelaçamentos de copas, as larguras das ruas e dos passeios, e os problemas ocasionados pela raiz,

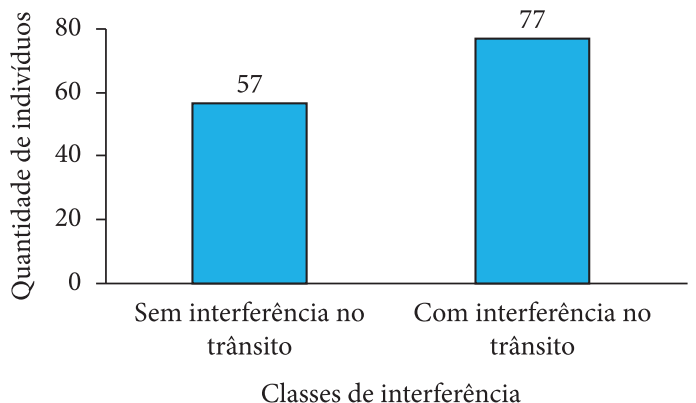

Figura 8. Distribuição das classes de interferências das copas dos exemplares inventariados da Avenida Celestino Cavalheiro, São Gabriel-RS e frequências relativas.

Figure 8. Distribution of class of interference by canopy of the plant species of tree planting Celestino Cavalheiro Avenue, São Gabriel-RS and absolute frequencies.

não chegando a números consideráveis (Raber \& Rebelato, 2010).

Analisando-se individualmente, por espécie inventariada, observa-se na Figura 9 que o Ligustro e a Extremosa são as que apresentam os maiores problemas de interferência no trânsito, em função de terem exemplares plantados há mais tempo e com maior porte; como consquência, há projeção de suas copas, obstaculizando o fluxo de veículos de grande porte que geram danos na copa, nos ramos e no caule. Cabe destacar o Ipê-roxo, a Canafístula e o Angico-vermelho por serem árvores de grande porte e que apresentam interferência no trânsito, embora com menor destaque por causa do menor número de exemplares.

Embora a classe compatível, isoladamente, contemple o maior número de indivíduos inventariados (49), conforme a Figura 10, por existirem muitos de porte pequeno e que ainda não apresentam sinais de conflitos com estruturas viárias e fluxo de trânsito, a análise do contexto geral permite outra inferência. Deve-se considerar que as demais classes possuem uma quantidade significativa de exemplares arbóreo-arbustivos (85) em diferentes condições de incompatibilidade, corroborando as análises de interferência no trânsito, altura do fuste e altura total, e demonstrando assim os conflitos da vegetação com o fluxo de veículos e equipamentos urbanos que circundam a mesma. 


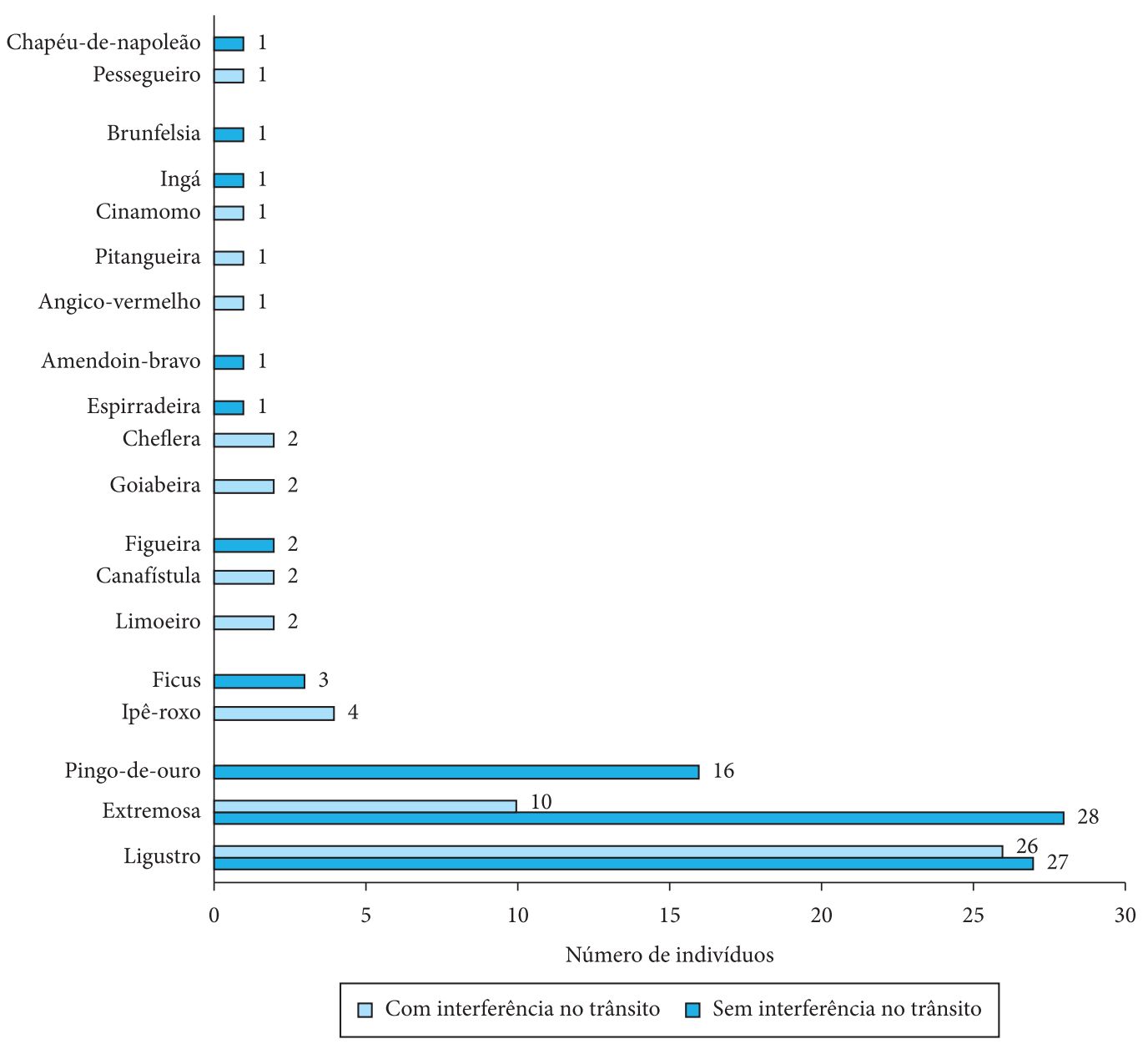

Figura 9. Distribuição das classes de interferência das copas por espécie vegetal da arborização da Avenida Celestino Cavalheiro, São Gabriel-RS e suas frequências absolutas.

Figure 9. Distribution of class of interference by the canopy of the plant species of tree planting Celestino Cavalheiro Avenue, São Gabriel-RS and their absolute frequencies.

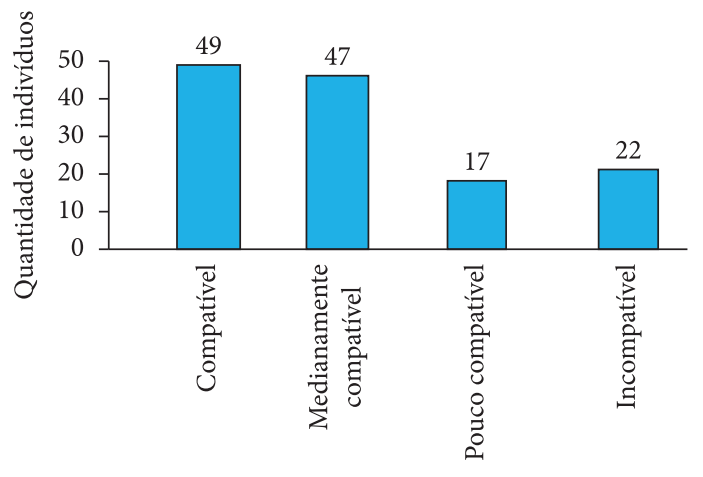

Classes de compatibilidade

Figura 10. Distribuição das classes de compatibilidade com frequências relativas dos exemplares da arborização da Avenida Celestino Cavalheiro, São Gabriel-RS.

Figure 10. Distribution of compatibility class and with relative frequencies exemplary arborization Celestino Cavalheiro Avenue, São Gabriel-RS.
Sucomine \& Sales (2010) comentam que, no estudo da área central de São Carlos-SP, das 1977 árvores adultas estudadas, 899 (mais de 45\% da população total) apresentaram um ou mais conflito com o entorno. Vale salientar que os resultados de integridade física e de compatibilidade dos vegetais com o entorno atingiram níveis aceitáveis e satisfatórios, sendo que isso deve estar relacionado ao fato de a arborização analisada ser formada basicamente por indivíduos jovens e por mudas que ainda não atingiram o pleno desenvolvimento de suas copas e raízes. Tal fato contribuiu para reduzir os conflitos com a fiação e com o calçamento, considerados incipientes e, dessa forma, minimizou os problemas de implantação e a necessidade de correções essenciais para o planejamento. 


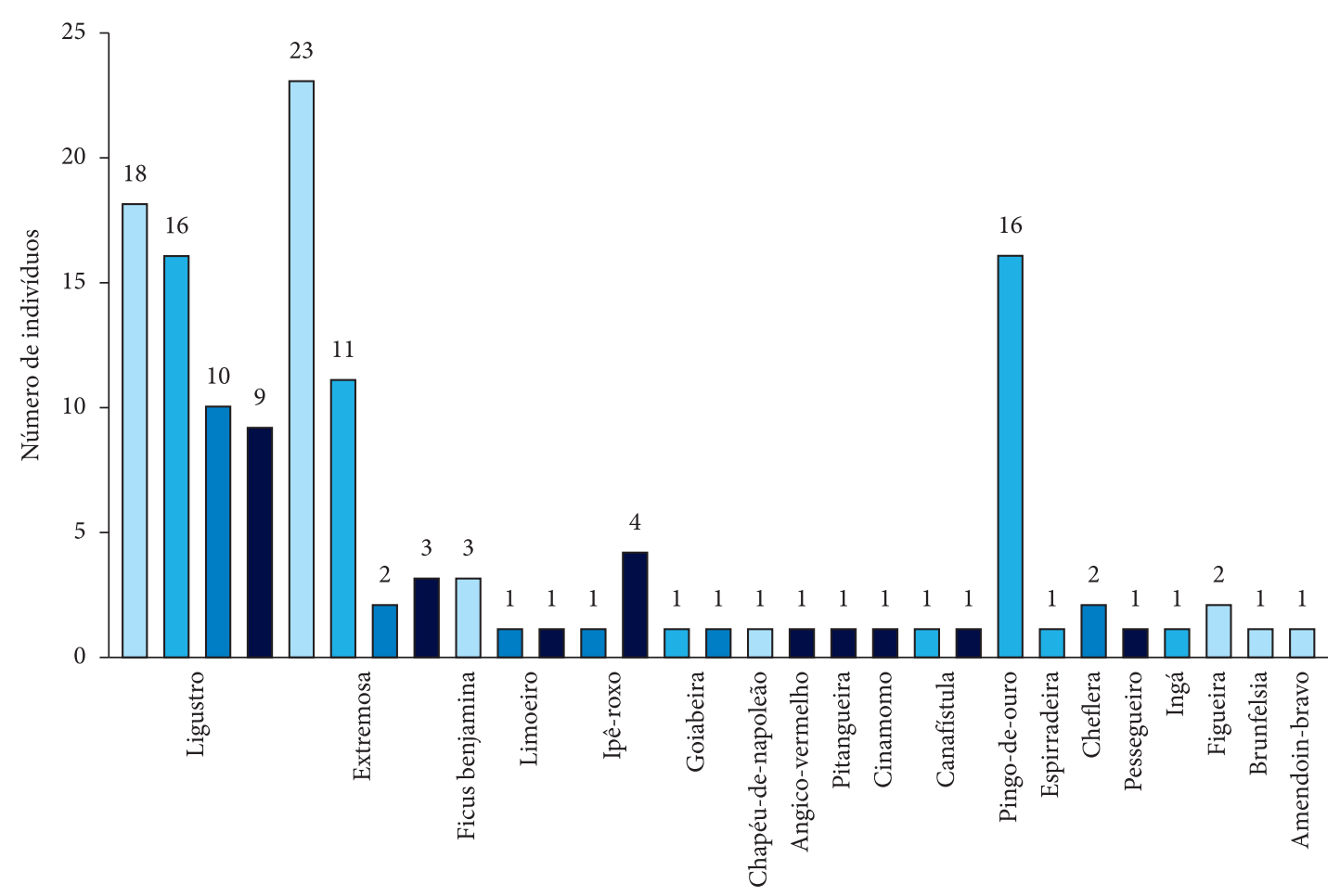

$$
\text { Compatível } \square \text { Medianamente compatível } \square \text { Pouco compatível } \square \text { Incompatível }
$$

Figura 11. Distribuição das frequências absolutas das categorias de compatibilidade por espécie inventariada da arborização da Avenida Celestino Cavalheiro, São Gabriel-RS.

Figure 11. Distribution of absolute frequencies of the categories compatibility inventoried by species of tree planting Celestino Cavalheiro Avenue, São Gabriel-RS.

Analisando-se individualmente os dados da Figura 11, observa-se que ocorrem várias espécies com exemplares na categoria de incompatibilidade, sendo que Angico-vermelho, Pitangueira, Cinamomo e Pessegueiro possuem todos os seus indivíduos incompatíveis. Tal situação deriva da posição em que se encontram em relação às estruturas circundantes que alteram sua arquitetura ou até mesmo da condição de plantio inadequado, em que ocorrem sobreposições de copas impedindo o correto crescimento do exemplar.

Mascaró \& Mascaró (2010) comentam que a vegetação urbana também pode provocar diversos inconvenientes, fundamentalmente pela falta de conhecimento sobre a conveniência de qual espécie plantar em determinados climas locais e microclimas urbanos, pela falta de harmonia com a infraestrutura urbana e de manutenção adequada, tanto do ponto de vista fitossanitário como formal.

\section{CONCLUSÕES}

A análise da compatibilidade da vegetação arbóreo-arbustiva que compõe a arborização da Avenida Celestino Cavalheiro, no município de São Gabriel-RS, demonstrou que urge um plano de manejo com intervenções silviculturais para a mesma. Esse processo permitirá manter ainda os exemplares de porte grande em conformidade com o espaço existente e possibilitará aos pequenos um crescimento compatível, evitando os conflitos futuros, ampliando a vida útil dos mesmos e potencializando o exercício de suas funções ambientais na plenitude.

\section{STATUS DA SUBMISSÃO}

Recebido: 11/08/2011

Aceito: 14/11/2011

Resumo publicado online: 16/11/2011

Artigo completo publicado: 22/12/2011 


\section{AUTOR(ES) PARA CORRESPONDÊNCIA}

\section{Italo Filippi Teixeira}

Universidade Federal do Pampa - UNIPAMPA, Av. Antonio Trilha, 1847, Campus São Gabriel, CEP 97300-000,

São Gabriel, RS, Brasil

e-mail: italo.filippi@gmail.com

\section{REFERENNCIAS}

Almeida ALBSSSL. O valor das árvores: árvores e floresta urbana de Lisboa. Lisboa: Universidade Técnica de Lisboa, Instituto Superior de Agronomia; 2006. 342 p.

Biondi D. Diagnóstico da arborização de ruas da Cidade de Recife [dissertação]. Curitiba:Universidade Federal do Paraná; 1985.

Bonametti JH. Arborização urbana. Terra $e$ Cultura 2003;(36):51-55.

Chacel F. Paisagismo, conservação da natureza e ecologia. In: Associação Brasileira De Arquitetos Paisagistas - ABAP. Apostila do Curso de Paisagismo. São Paulo: ABAP; 2004.

Cruz PMF, Sousa HA, Carvalho JOP, Brito JS. Analise quali-quantitativa da arborização urbana da Avenida Marechal Castelo Branco em Teresina-PIAUÍ. In: Anais do III Congresso de Pesquisa e Inovação da Rede Norte Nordeste de Educação Tecnológica; 2008, Fortaleza. Fortaleza: CEFET, 2008

Curitiba. Prefeitura Municipal. Departamento de Parques e Jardins - DPJ. Arborização urbana da Cidade de Curitiba. Curitiba: PMC; 1977. 6 p.

Da Silva SI. Diagnóstico da arborização urbana em vias públicas no município de Foz do Iguaçu-PR[monografia]. Foz do Iguaçu: Faculdade Dinâmica de Cataratas; 2009.

Duryea ML, Blakeslee GM, Hubbard WG, Vasquez R. A Wind and Trees: A survey of homeowners after hurricane Andrew. Journal of Arboriculture 1996; 22(1):44-49.

Flores GJA. El arbolado urbano en el área metropolitana de Monterrey. San Nicolás de los Garza. Ciencia UANL 2005; (1):20-32.

Fostad O, Pedersen PA. Vitality, variation, and causes of decline of trees in Oslo Center (Normay). Journal of Arboriculture 1997; 23(4):155-165.

Instituto Brasileiro de Geografia e Estatística. Cidades. [cited 2011 abr. 8]. Available from: http://www.ibge.gov. br.

Magalhães MR.A Arquitectura Paisagista, morfologia e complexidade. Lisboa: Editorial Estampa; 2001. p. 382383.
Martins LFV. Analise da arborização de acompanhamento viário em uma cidade de pequeno porte: Luiziana, Paraná [dissertação].Maringá: Universidade Estadual de Maringá; 2010.

Mascaró L, Mascaró JL. Vegetação urbana. 3rd ed. Porto Alegre: Masquatro Editora; 2010. 212 p.

Mcpherson G, Nowak D, Rowntree R. Chicago's urban forest ecosystem: results of the Chicago urban forest climate project. USDA Forest Service; 1994.General Technical Report Northeastern Forest Experiment Station, n. NE-186.

Melo EFRQ, Severo BMA. Avenida Brasil (Passo Fundo, Rio Grande do Sul):diversidade da vegetação e qualidade ambiental. REVSBAU 2010; 5(3):1-17.

Menegat R, Porto ML, Carraro CC, Fernandes LAD. Atlas Ambiental de Porto Alegre. 2rd ed. Porto Alegre: Editora da Universidade; 1999. 297p.

Milano MS. Avaliação quali-quantitativa e manejo da arborizaçào urbana: exemplo de Maringá-PR [tese]. Curitiba: Universidade Federal do Paraná; 1988.

Miller R. Multiple use urban forest management in the Federal Republic of Germany. Milwaukee: Man and Biosphere Seminar; 1983. p. 21-24.

Nicodemo MLF, Primavesi O. Por que manter árvores na área urbana? São Carlos: Embrapa Pecuária Sudeste; 2009. 40 p.

Nowak DJ. The effects of Urban Forests on the Physical Environment. In: Proceedings of the IUrban Forests and Trees; 2001, Bruxelles. Bruxelles: European Communities; 2001.p. 22.

Pereira RI. O sentido da paisagem e a paisagem consentida: projetos participativos na produção do espaço livre público [tese].São Paulo: Universidade de São Paulo; 2006.

Raber AP, Rebelato GS. Arborização viária do município de Colorado-RS - Brasil: análise quali-quantitativa. REVSBAU 2010; 5(1):183-190.

Rego JLES. Tipologias de espaços exteriores de Lisboa. Lisboa: Instituto Superior de Agronomia, Universidade Técnica de Lisboa; 1984. Relatório final do Curso Livre de Arquitectura Paisagista.

Rocha RT, Leles PSS, Oliveira Neto, SN. Arborização de vias púbicas em Nova Iguaçu, RJ: o caso dos bairros Rancho Novo e Centro. Revista Árvore 2004; 28(4). http://dx.doi.org/10.1590/S0100-67622004000400014

Rodolfo Junior F, Melo RR, Cunha TA, Stangerlin DM. Análise da arborização urbana em bairros da cidade de Pombal no Estado da Paraíba. REVSBAU 2008; 3(4)3-19.

Santiago CA. Arborização das Cidades. Campinas; 1970. Boletim Técnico, n. 90.

Sampaio ACF. Análise da arborização de vias públicas das principais zonas do plano piloto de Maringá-PR 
[dissertação]. Maringá: Universidade Estadual de Maringá; 2006.

Silva AG. Arborização urbana em cidades de pequeno porte: avaliação quantitativa e qualitativa [dissertação]. Viçosa: Universidade Federal de Viçosa; 2000.

Silva LM, Hasse I, Cadorin DA, Oliveira KA, Oliveira FAC, Bett CF. Inventario da arborização em duas vias de Mariópolis/PR. REVSBAU 2008; 3(1):36-53.

Sucomine NM, Sales A. Caracterização e análise do patrimônio arbóreo da malha viária urbana central do município de São Carlos-SP. REVSBAU 2010; 5(4):128140.
Turra JH, Baggio PM; Rodrigues JP,Ourique LK, Costa LM, Fonseca RBP, Ferreto DO, Posser DM, Teixeira IF. Estudo de caso: Avenida das Acácias, Jardim Europa, município de São Gabriel RS. In: Anais do II Salão Internacional de Ensino, Pesquisa e Extensão; 2010, Uruguaiana. Uruguaiana: UNIPAMPA; 2010. 1 CDROM.

Velasco GDN. Arborização viária X sistemas de distribuição de energia elétrica: avaliação dos custos, estudo das podas e levantamento de problemas fitotécnicos [dissertação]. Piracicaba: Escola Superior de Agricultura Luis de Queiroz, Universidade de São Paulo; 2003. 